\title{
Pendidikan Anti Korupsi Bagi Pelajar
}

\author{
Hesti Widyaningrum ${ }^{1,}{ }^{*}$, Adi Nur Rohman ${ }^{1}$, Sugeng ${ }^{1}$, Elfirda Ade Putri ${ }^{1}$ \\ ${ }^{1}$ Fakultas Hukum, Universitas Bhayangkara Jakarta Raya; Jl. Raya Perjuangan, Marga Mulya, \\ Bekasi Utara, Jawa Barat 17121. Telp: 021-88955882, 889955883, e-mail: \\ hestiwidyaningrum01@gmail.com; e-mail: adinurrohman@yahoo.co.id; e-mail: \\ sugeng@dsn.ubharajaya.ac.id; e-mail: elfirdadade.putri@gmail.com \\ * Korespondensi: e-mail: hestiwidyaningrum01@gmail.com
}

\begin{abstract}
Corruption crime can not only be minimized through the eradication of corruption, such as through law enforcement, but also needs precaution that is no less important. Therefore, the community plays an important role in preventing these crimes. Various elements that exist in society, civita academics can also participate in supporting building anti-corruption behavior. Lecturers and Students can be involved in this through Community Service activities as part of the Higher Education Tri Dharma. Various ways can be done and one of them is by providing early education for students in recognizing anti-corruption behavior and its importance for the nation and state. The Legal Counseling Activity regarding Anti-Corruption Education for Students was held at the Global Prima Islamic School Vocational School which was attended by approximately 59 Participants. After delivering the material and questionnaire to the participants, it can be seen that anti-corruption education is really needed to students because based on the questionnaire distributed, it turns out students do not know the relationship of dishonesty with corrupt behavior as evidenced from the results of the questionnaire that most students stated that cheating is not corrupt behavior. Through the material delivered at the time of counseling that cheating is one of the dishonest behaviors that is the seed of a corrupt attitude and can be the seeds of corruption crime in the future and the impact that occurs on the behavior of corruption. Regarding this, based on the results of the questionnaire, the majority of participants stated that the behavior of corruption had a more complex effect on the nation and state.
\end{abstract}

Keywords: Education, Anti-Corruption, Students

\begin{abstract}
Abstrak
Kejahatan Korupsi tidak hanya dapat diminimalisir melalui pemberantasan korupsi semata seperti melalui penegakan hukum namun juga perlu tindakan pencegahan yang tidak kalah pentingnya. Oleh karena itu, masyarakat sangat berperan dalam pencegahan kejahatan tersebut. Berbagai elemen yang ada di masyarakat, civita akademika juga dapat ikut berpartisipasi dalam mendukung membangun prilaku anti korupsi. Dosen dan Mahasiswa dapat terlibat dalam hal ini melalui kegiatan Pengabdian Kepada Masyarakat sebagai bagian dari Tri Dharma Perguruan Tinggi. Berbagai cara dapat dilakukan dan salah satunya dengan cara memberikan pendidikan dini bagi pelajar dalam mengenal prilaku anti korupsi dan pentingnya bagi bangsa dan negara. Kegiatan Penyuluhan Hukum mengenai Pendidikan anti Korupsi bagi Pelajar ini telaksana di SMK Global Prima Islamic School yang diikuti lebih kurang 59 Peserta. Setelah disampaikannya materi dan kuisioner kepada peserta, maka dapat diketahui bahwa pendidikan anti korupsi sangat diperlukan kepada pelajar karena berdasarkan kuisioner yang dibagikan ternyata pelajar belum mengetahui hubungan sikap tidak jujur dengan prilaku korupsi yang dibuktikan dari hasil kuisioner bahwa sebagian besar pelajar menyatakan bahwa menyontek bukan prilaku korupsi. Melalui materi yang disampaikan pada saat penyuluhan bahwa menyontek adalah salah satu prilaku tidak jujur yang menjadi bibit dari sikap korup dan dapat menjadi bibit kejahatan korupsi di masa mendatang serta dampak yang terjadi atas prliaku korupsi. Atas hal ini, Berdasarkan hasil kuisioner itu juga, sebagian besar peserta menyatakan bahwa prilaku korupsi berdampak lebih komplek terhadap bangsa dan negara.
\end{abstract}


Kata Kunci: Pendidikan, Anti Korupsi, Pelajar

\section{Pendahuluan}

Kejahatan korupsi sering sekali terjadi di Indonesia, pelakunya tidak hanya melibatkan Pejabat seperti Walikota, Gubernur, namun juga Anggota Dewan Perwakilan Rakyat bahkan Penegak Hukum hingga Kepala Desa ikut terlibat korupsi (Laporan Tahun KPK, 2017). Banyaknya kasus korupsi di Indonesia, mendorong pemerintah beserta Penegak hukum, melakukan berbagai cara untuk melakukan pemberantasan dan pencegahan terhadap kejahatan korupsi yang ibaratnya seperti "wabah."

Kondisi ini mendorong pemerintah untuk mengkriminalisasi kejahatan korupsi sebagai tindak pidana yang berkosekuensi pidana sebagaimana diatur dalam Undang-Undang Nomor 31 Tahun 1999 tentang Pemberantasan Tindak Pidana Korupsi yang kemudian diperbaharui kembali dengan Undang-Undang Nomor 20 Tahun 2001. Diberlakukannya undang-undang ini menuntut adanya lembaga khusus yang menangani kejahatan ini karena kejahatan ini bukan lagi permasalahan di Indonesia semata, namun juga permasalahan global (Hongying Wang dan James N. Rosenau, 2001).

Akhirnya, pemerintah membentuk lembaga yang dinamakan Komisi Pemberantasan Korupsi (KPK). Sebagai Lembaga yang independen, maka lembaga ini diharapakan mampu meminimalisir kejahatan korupsi yang ada di Indonesia( Risalah DPR RI, 2002). Capaian kinerja KPK pun telah disampaikan oleh salah Satu pimpinan KPK pada perayaan Hari Anti Korupsi Internasional (HARKODIA) Akhir tahun 2018 lalu bahwa Index Presepsi korupsi di Indonesia sejak tahun 1998 hingga 2018 sudah meningkat menjadi 37 dari 20 (Dylan, 1 Februari 2019).

Banyaknya pelaku korupsi di Indonesia yang tidak hanya puluhan bahkan ratusan, mengisyaratkan bahwa permasalahan kejahatan korupsi tidak mampu diselesaikan hanya pada titik pemberantasan semata melainkan juga dibutuhkan pencegahan sedini mungkin. Selain itu, persoalan ini tidak mampu hanya digantungkan bebannya kepada Pemerintah berserta Penegak Hukum, dan KPK semata, namun juga dibutuhkan partisipasi dan kerjasama masyarakat untuk terlibat di dalam Pemecahan permasalahan korupsi yang belum kunjung terselesaikan. Peran masayarakat sangat penting dalam pencegahan kejahatan korupsi.

Hal ini juga sebenarnya sudah diinisiasi oleh KPK dalam berbagai bentuk kegiatan seperti mendorong perbaikan tata kelola pemerintahan di berbagai Daerah, perbaikan sistem perizinan investasi berbasis online, hingga melakukan berbagai kajian dalam sistem pengelolaan administasi di sektor pangan, listrik, Kesehatan, kehutanan, dan pajak (Laporan KPK, 2016). Berbagai upaya pencegahan yang telah dilakukan oleh KPK membuat KPK meraih Anti Corruption Excellence Award 2017 atas inisiasi KPK dalam melibatkan perempuan dalam pencegahan korupsi dengan nama gerakan barunya "Saya perempuan Anti Korupsi" (Putra, 1 Januari 2019). 
Walau berbagai upaya KPK dalam melakukan pemberantasan dan pencegahan korupsi terhitung telah mencapai banyak perubahan, akan tetapi peran masyarakat masih sangat dibutuhkan dalam menuju peringkat negara bersih dari korupsi yang lebih tinggi seperti Singapure, Finlandia, Denmark, dan sebagainya. Tentu, hal ini membutuhkan waktu dan proses yang tidak singkat. Oleh karena itu dibutuhkan pencegahan yang dini, agar kajahatan korupsi tidak menjadi "wabah" yang semakin mengakar di Indonesia. Tidak berbeda dengan pola pencegahan korupsi yang dilakukan oleh KPK dengan mendorong kesadaran anti korupsi terhadap perempuan, Penulis kiranya juga dibutuhkan kesadarakn anti korupsi yang lebih dini lagi yang tidak hanya melibatkan dalam sisi "gender" namun juga pada usia muda. Hal ini ditujukan agar pengetahuan anti korupsi sudah dikenal pada jenjang pelajar seperti Sekolah Menengah Atas. Partisipasi masyarakat dalam pencegahan korupsi juga dibutuhkan dari pelajar sebagai remaja yang notabene adalah pengguna tertinggi internet. Melalui Pelajar ini, diharapkan mereka dapat mengetahui lebih dini mengenai pentingnya prilaku anti korupsi dan juga dapat menyebarluaskan kesadaran anti korupsinya kepada masyarakat sehingga dapat mendorong kegiatan positif bagi pelajar itu sendiri. Upaya ini dapat dilakukan melibatkan Akademisi dalam peningkatan kesadaran anti korupsi bagi pelajar melalui Penyuluhan. Ini juga dapat menjadi bagian dalam pelaksanaan Tri Dharma Perguruan Tinggi.

\section{Metode Pelaksanaan}

Pelaksanaan kegiatan ini pada tanggal 16 Januari 2020, disampaikan kepada 59 orang Pelajar di SMK Global Prima Islamic School, Bekasi. Para peserta mengikuti kegiatan dengan bentuk Penyuluhan mengenai Pendidikan Anti Korupsi untuk mengenal prilaku anti korupsi, dampak dan pencegahannya. Untuk mengetahui tingkat pemahaman peserta penyuluhan terhadap materi yang disampaikan, diserahkan kuisioner kepada peserta pada saat sebelum kegiatan dilaksanakan. Hal ini diperlukan agar pelaksanaan dari penyuluhan ini dapat berjalan dengan efektif.

\section{Hasil dan Pembahasan}

Kegiatan Pengabdian kepada Masyakat ini dilaksanakan pada Tanggal 16 Januari 2020 di SMK Global Prima Islamis School, Bekasi Utara. Kegiatan ini dilaksanakan dimulai pada Pukul 09.00 hingga selesai. Peserta pada kegiatan ini berjumlah 59 murid. Siswi lebih dominan dalam mengikuti kegiatan ini dibandingkan siswa. Murid pada kegiatan ini diikuti dari kelas XI. Oleh karena pada kegiatan ini ditujukan untuk memberikan kesadaran anti korupsi bagi pelajar, maka pada saat pelaksanaan kegiatan tim membagikan kuisioner kepada peserta. Peserta ini terdiri dari 21 dari murid laki-laki, dan 38 murid perempuan Hasil dari kuisioner ini dijelaskan pada Tabel 1. 
Tabel 1. Hasil Kuesioner

\begin{tabular}{|c|c|c|c|}
\hline Perempuan & $\begin{array}{l}90 \% \text { pernah berbohong } \\
\text { kepada Orang Tua karena } \\
\text { terlambat pulang }\end{array}$ & $\begin{array}{l}90 \% \text { pernah menyontek } \\
\text { sebagai bentuk } \\
\text { berbohong yang pernah } \\
\text { dilakukan kepada guru }\end{array}$ & $\begin{array}{l}90 \% \text { menganggap } \\
\text { menyontek bukan bentuk } \\
\text { dari perbuatan korupsi }\end{array}$ \\
\hline Laki-laki & $\begin{array}{l}90 \% \text { pernah berbohong } \\
\text { kepada orang tua karena } \\
\text { terlambat pulang }\end{array}$ & $\begin{array}{l}90 \% \text { pernah menyontek } \\
\text { sebagai } \quad \text { bentuk } \\
\text { berbohong yang pernah } \\
\text { dilakukan kepada guru }\end{array}$ & $\begin{array}{l}90 \% \text { menganggap } \\
\text { menyontek bukan bentuk } \\
\text { dari perbuatan korupsi }\end{array}$ \\
\hline
\end{tabular}

Hasil ini menjelaskan bahwa sebelum dijelaskan mengenai hubungan ketidakjujuran dengan kesadaran anti korupsi, ternyata sebagian peserta baik perempuan dan laki-laki pernah melakukan perbuatan tidak jujur, yakni berbohong dan menyontek. Semuanya menyadari bahwa menyontek bukan perbuatan yang baik, namun peserta belum mengetahui hubungan sikap anti korupsi dengan ketidakjujuran.

Oleh karena itu, pemateri menjelaskan bagaimana kesadaran anti korupsi itu tumbuh dari sikap jujur. Ketidakjujuran yang sering dilakukan oleh pelajar dapat berbagai bentuk seperti, menyontek, berbohong ketika terlambat sekolah atau bolos sekolah, dsb. Selain itu juga pemateri menyampaikan beberapa hal seperti definisi korupsi pada dasarnya berasal dari kata corruptio atau corruptus yang artinya ketidakjujuran, keburukan, dan penyimpangan dari hal-hal yang baik (Hamzah, 2017).

Dengan demikian, pelajar perlu disampaikan makna itu sehingga pemahaman soal menyontek juga dapat menjadi bagian dari bibit prilaku yang korup. Selain itu juga pemateri menyampaikan bahwa prilaku jujur jika terus dilakukan akan berdampak terjadinya tindak pidana korupsi di Indonesia. Jika terjadi maka Indonesia tidak pernah menjadi negara yang bersih dari korupsi dimana masih di angka 38 (Indeks Persepsi Korupsi Data Trasparansi Internasional, 15 Desember 2015). Karena itu, pentingnya kesadaran anti korupsi ini ditanamkan kepada pelajar agar prilaku anti korupsi dikenal sejak dini, sehingga meminimalisir perbuatan korupsi yang terjadi di Indonesia. Untuk itu, maka pemateri juga menyampaikan beberapa dampak yang terjadi:

a. Segi Aspek Ekonomi yang berdampak pada penurunan pendapatan pajak, penurunan produktivitas, rendahnya kualitas jasa dan barang publik, serta peningkatan hutang negara.

b. Segi Sosial dan Kemiskinan berdampak pada peningkatan kemiskinan, terbatasnya akses layanan masyarakat miskin, hubungan sosial menjadi langka dan sebagainya

c. Segi Politik dan Demokrasi berdampak semakin sulitnya mempunyai calon pemimpin yang bersih dan sesuai dengan kemampuan dalam memimpin (Infografis Dampak Korupsi, 15 Desember 2019).

Selain itu juga pemateri juga menyampaikan bahwa dalam Undang-Undang Pemberantasan Tindak Pidana Korupsi, terdapat beberapa jenis Tindak Pidana Korupsi yakni:

a) Suap-Menyuap

b) Pemerasan 
c) Perbuatan Curang

d) Gratifikasi, dsb (Prandjonggo, 2010).

Hal-hal ini perlu dijelaskan kepada peserta agar peserta memahami betap buruknya korupsi itu dan bentuk yang mana yang dapat dihukum sebagaimana diatur dalam UndangUndang. Hukuman juga dijelaskan oleh pemateri sebagaimana jenis-jenisnya seperti Denda, Pidana Penjara, bahkan Pidana Mati.

Pasca penyampaian materi kepada peserta, tim juga memberikan kuisioner untuk mengukur apakah peserta memahami materi yang disampaikan. Hasilnya bahwa:

Tabel 2 Hasil Kuesioner pemahaman materi

\begin{tabular}{lllll}
\hline Jenis Kelamin & $\begin{array}{l}\text { Pengetahuan soal Dampak } \\
\text { kepada masyarakat }\end{array}$ & $\begin{array}{l}\text { Keuntungan dari prilaku } \\
\text { jujur dan anti korupsi }\end{array}$ & $\begin{array}{l}\text { Respon } \\
\text { Korupsi }\end{array}$ & atas \\
\hline Perempuan & $\begin{array}{l}80 \% \text { menyatakan bahwa dampak } \\
\text { dari korupsi itu adalah sangat } \\
\text { merugikan bangs dan negara } \\
\text { terutama pendapatan pajak negara } \\
\text { sehinggara negara tidak maju }\end{array}$ & $\begin{array}{l}90 \% \text { menyatakan dapat } \\
\text { dipercaya orang lain. }\end{array}$ & $\begin{array}{l}100 \% \text { menyatakan } \\
\text { lawan korupsi }\end{array}$ \\
& $\begin{array}{l}20 \% \text { menyatakan dampak dari } \\
\text { korupsi merugikan orang lain }\end{array}$ & & \\
& $\begin{array}{l}90 \% \text { menyatakan dampak dari } \\
\text { korupsi merugikan orang lain. }\end{array}$ & $\begin{array}{l}90 \% \text { menyatakan dapat } \\
\text { dipercaya orang lain. }\end{array}$ & $100 \%$ menyatakan \\
& $\begin{array}{l}\text { lawan korupsi } \\
\text { kaki-laki }\end{array}$ & & \\
\hline Sumberupsi merugikan negara
\end{tabular}

Kemudian pemateri juga menyampaikan bagaimana cara praktis yang dapat dilakukan para pelajar dalam meningkatan kesadaran anti korupsi sebagai wujud melawan perbuatan korupsi sebagai berikut: 1). Mengadakan teater bertemakan anti korupsi, 2). Membuat kantin Jujur di Kelas atau di Sekolah, 3). Membuat lagu/musik yang bertemaan anti korupsi. 4). membuat film pendek bertemakan anti korupsi (International Trancparancy, 15 Desember 2019).

Dari keempat pilihan cara yang dapat dilakukan pelajar dalam meningkatkan kesadarkan anti korupsi kepada orang lain, 90\% peserta lebih memilih pembuatan film pendek yang bertemakan anti korupsi.

\section{Kesimpulan}

Berdasarkan hasil pelaksanaan kegiatan Pengabdian kepada Masyarakat ini dapat disimpulkan beberapa hal: a). Perlunya memberikan kesadaran prilaku anti korupsi kepada pelajar bahwa ternyata pelajar belum mengetahui hubungan sikap tidak jujur dengan prilaku korupsi yang dibuktikan dari hasil kuisioner bahwa sebagian besar pelajar menyatakan bahwa menyonte bukan prilaku korupsi. Selain itu, Pelajar laki-laki sebagian besar memahami bahwa korupsi hanya menimbulkan kerugian bagi orang lain, sedangkan pelajar perempuan memahami bahwa prilaku korupsi berdampak lebih komplek terhadap bangsa dan negara. b). 
Kesadaran anti korupsi perlu ditanamkan kepada pelajar sebagai bentuk pencegahan dari tindak pidana korupsi di masa mendatang. Oleh karena itu butuh keterlibatan pelajar dalam berpartipasi meningkatkan kesadaran tersebut. Ternyata dari 4 (empat) pilihan yang dicontohkan kepada peserta, sebagian besar Pelajar lebih memilih cara yang dapat meningkatkan kesadarkan anti korupsi melalui pembuatan film pendek bertemakan anti korupsi.

Selain itu juga, berdasarkan hasil pelaksanaan kegiatan in maka rekomendasinya yakni: 1). Bagi Dosen maupun mahasiswa yang ingin melaksanakan kegiatan yang bertemakan anti korupsi dapat dilakukan dengan cara-cara yang lebih kreatif sehingga peserta tidak merasa jenuh dan langsung terlibat dalam kegiatan yang membantu peningkatan kesadaran anti korupsi kepada orang lain. 2). Pengajaran kesadaran anti korupsi mestinya tidak hanya dilaksanakan di Sekolah Menengah saja, namun dapat dilaksanakan di level Sekolah Menengah Pertama bahkan Sekolah Dasar.

\section{Ucapan Terima Kasih}

Penulis mengucapkan terima kasih sebesar-besarnya kepada Universitas Bhayangkara Jakarta Raya yang selalu mendukung baik secara immateril dan materil (dana) atas kegiatan ini. Selain itu juga Penulis mengucapkan terima kasih kepada pihak Sekolah SMK Global Prima Islamic School yang bersedia dengan senang hati untuk menerima dalam pelaksanaan kegiatan ini.

\section{Daftar Pustaka}

Hamzah, Andi. (2014). Pemberantasan Korupsi. Jakarta: Raja Grafindo Persada.

Laporan Tahun KPK. (2016).

Laporan Tahun KPK. (2017).

Pradjonggo, Tjandra Sridjaja. (2010). Sifat Melawan Hukum dalam Tindak Pidana Korupsi. Jakarta: ILC.

Risalah Rapat Paripurna dalam Pembahasan tentang Komisi Pemberantasan Tindak Pidana Korupsi (2002).

Wang, Hongying dan James N. Rosenau. (2001). "Transparancy Internasional and Corruption as an Issue of Global Governance". Global Governance Journal. Vol. 7 No. 21.

Dylan, Aprialdo Rachman. (1 Januari 2019).

"KPK dan 4 Kementrian Sepakati Implementasi Pendidikan Antikorupsi," <https://nasional.kompas.com/read/2018/12/11/15331641/kpk-dan-4-kementeriansepakati-implementasi-pendidikan-antikorupsi.>

"Persepsi Korupsi Data Trasparansi Internasional". (15 Desember 2015). <www. ti.or.id>.

"Infografis Dampak Korupsi". (15 Desember 2019). <https://aclc.kpk.go.id/materi/bahaya-dandampak-korupsi>. Diakses tanggal.

International Transparancy. (15 Desember 2019). "15 Ways Young People Can Fight Corruption".

$<$ https://www.transparency.org/news/feature/15_ways_young_people_can_fight_corruptio $\mathrm{n}>$.

Putra, Muhammad Andika. (1 Januari 2019). "Saya Perempuan Anti Korupsi Raih Penghargaan Internasional." <https://www.cnnindonesia.com/nasional/20171209173631-20261334/saya-perempuan-anti-korupsi-raih-penghargaan-internasional>. 